\title{
Características produtivas de capim-elefante sob doses de fósforo e nitrogênio para fins energéticos
}

\section{Productive Characteristics of Elephant grass under Doses of Phosphorus and Nitrogen for Energy Purposes}

\author{
Marcia Maria Paes SANTOS ${ }^{1 ; 2}$; Rogério Figueiredo DAHER ${ }^{3}$; Niraldo José PONCIANO ${ }^{4}$; \\ Geraldo de Amaral GRAVINA ; Antônio Vander PEREIRA ${ }^{6}$; \\ José Augusto de Almeida SANT'ANA ${ }^{7}$; Carlos Lacy SANTOS ${ }^{8}$ \\ ${ }^{1}$ Parte da Tese da primeira autora. Pesquisa financiada parcialmente pela Fundação de Amparo à Pesquisa do \\ Estado do Rio de Janeiro (FAPERJ) \\ ${ }^{2}$ Autora para correspondência - Doutora em Produção Vegetal pela Universidade Estadual do Norte Fluminense Darcy \\ Ribeiro - UENF (RJ). Professora do IFES Campus de Alegre (ES), marciapaessantos@yahoo.com.br \\ ${ }^{3}$ Doutor em Produção Vegetal pela Universidade Estadual do Norte Fluminense Darcy Ribeiro - UENF (RJ). Professor \\ Associado LEAG/CCTA/UENF. Setor de Estatística e Experimentação Agropecuária. rogdaher@uenf.br \\ 4 Doutor em Economia Rural pela Universidade Federal de Viçosa - UFV (MG). Professor Associado \\ LEAG/CCTA/UENF. Setor de Economia Rural. ponciano@uenf.br \\ ${ }^{5}$ Doutor em Fitotecnia pela Universidade Federal de Viçosa - UFV (MG). Professor Associado LEAG/CCTA/UENF. \\ Setor de Estatística e Experimentação Agropecuária. gravina@uenf.br; geraldo.gravina@pq.cnpq.br. \\ ${ }^{6}$ Doutor em Genética e Melhoramento de Plantas pela Escola Superior de Agricultura Luís de Queiroz - ESALQ \\ (SP). Pesquisador da Embrapa Gado de Leite. Empresa Brasileira de Pesquisa Agropecuária (Embrapa. Juiz \\ de Fora-MG). vander.pereira@embrapa.br \\ 7 Doutor em Produção Vegetal pela Universidade Estadual do Norte Fluminense Darcy Ribeiro - UENF (RJ). \\ Professor do IFES-Campus de Alegre - ES. jaasantana@ifes.edu.br \\ ${ }^{8}$ Mestre em Produção Vegetal pela Universidade Federal do Espírito Santo - UFES. Professor do IFES Campus \\ de Alegre (ES), Brasil. carloslacysantos@yahoo.com.br
}

Recebido em: 09-12-2013; Aceito em: 29-05-2014

\section{Resumo}

Em busca de fontes de energia mais eficientes, a biomassa do capim-elefante é uma alternativa. Objetivou-se avaliar efeitos de doses de fósforo e de nitrogênio em cultivares de capim-elefante, em delineamento de blocos casualizados, com esquema de parcelas subsubdivididas, com três repetições. As cultivares constituíram as parcelas, o fósforo as subparcelas e o nitrogênio as subsubparcelas. Observou-se ausência de significância para fósforo e suas interações, e significância para outros fatores. Pelo teste de Tukey a 5\%, 'Cameroon-Piracicaba' diferiu das demais no diâmetro do colmo e no número de plantas, e na largura de lâmina diferiu nas doses de 500 e $1.500 \mathrm{~kg} \mathrm{ha}^{-1}$ de N. Na dose de $500 \mathrm{~kg} \mathrm{ha}^{-1}$ de N, diferiu de 'Cana-D'África' na largura de lâmina, e esta diferiu de 'Guaçu/lZ.2' sem adubação nitrogenada. Na produção de matéria seca, o modelo ajustado para todas as cultivares foi o de segundo grau. As produtividades máximas de 15,62; 15,59 e 16,29 $\mathrm{t} \mathrm{ha}^{-1}$ foram obtidas com adubação de 817,$13 ; 1.039,47$ e $1.004,43 \mathrm{~kg} \mathrm{ha}^{-1}$ de $\mathrm{N}$, respectivamente. A cv. Cana-D'África apresentou ajuste significativo (segundo grau) para número de plantas, com perfilhamento máximo de 33 plantas $\mathrm{m}^{-1}$, na dose de $1.146,13 \mathrm{~kg} \mathrm{ha}^{-1}$ de $\mathrm{N}$, e linear para largura de lâmina. Entretanto, 'Cameroon-Piracicaba' teve largura máxima da lâmina foliar de 6,52 cm com 1.238,62 kg ha-1 de N.

Palavras-chave adicionais: análise de regressão; biomassa; características morfoagronômicas; cultivares; Pennisetum purpureum, Schum.

\begin{abstract}
In search of more efficient energy sources, the elephant grass biomass is an alternative. This study aimed to evaluate the effects of four doses of phosphorus and nitrogen on elephant grass cultivars, in a randomized block design, in split split plot scheme with three replications. The cultivars constituted the main plots, the phosphorus constituted the split plots, and nitrogen doses as split split plot. It was observed a lack of significance for phosphorus and its interactions, and no statistical significance for other factors. By Tukey test at 5\%, Cameroon-Piracicaba differed from the others in stem diameter and number of plants, and blade width differed in the doses 500 and $1500 \mathrm{~kg} \mathrm{ha}^{-1} \mathrm{~N}$. At dose of $500 \mathrm{~kg}$ $\mathrm{N}$ ha ${ }^{-1}$ it differed from Cana $\mathrm{D}$ 'Africa regarding to blade width, and differed from the Guaçu/IZ.2 without nitrogen fertilization. In dry matter production, the model was equation of $2^{\text {nd }}$ degree for all cultivars. The maximum productivities of $15.62,15.59$ and $16.29 \mathrm{t} \mathrm{ha}^{-1}$ were obtained respectively with fertilization of $817.13 ; 1039.47$ and $1004.43 \mathrm{~kg} \mathrm{ha}^{-1} \mathrm{~N}$. Only the cultivar Cana D'Africa presented a significant adjustment $\left(2^{\text {nd }}\right.$ degree) for number of plants, with maximum tillering of 33 plants $\mathrm{m}^{-1}$ at a
\end{abstract}


dose of $1146.13 \mathrm{~kg} \mathrm{ha}^{-1} \mathrm{~N}$, and linear for blade width. Moreover, Cameroon-Piracicaba had a maximum foliar blade width of $6.52 \mathrm{~cm}$ with $1238.62 \mathrm{~kg} \mathrm{ha}^{-1} \mathrm{~N}$.

Additional keywords: biomass; cultivars; morphoagronomic characteristics; regression analysis; Pennisetum purpureum, Schum.

\section{Introdução}

O capim-elefante (Pennisetum

purpureum, Schum) é uma monocotiledônea e, como tal, apresenta o colmo como uma parte fibrosa, mais dura, que forma a casca e uma medula com feixes vasculares. Sua estrutura morfológica é bastante semelhante à do bagaço de cana-de- -açúcar, o qual apresenta a seguinte composição: $65 \%$ de fibras e $35 \%$ de material não fibroso (AZEVEDO, 2000). É uma espécie de alto potencial energético, devido à otimização da energia solar pela planta. Esta característica é típica de poáceaes tropicais, de metabolismo $\mathrm{C} 4$, que crescem rapidamente e otimizam o uso da água, dos nutrientes do solo e da energia solar (LEMUS et al., 2002). Por apresentar um sistema radicular bem desenvolvido, pode contribuir de forma eficiente para aumentar o conteúdo de matéria orgânica do solo, ou o sequestro de C (carbono) no solo (URQUIAGA et al., 2006).

A queima da biomassa do capim-elefante como alternativa para a produção de energia renovável é devido ao fato de atingir 6 metros de altura em curto período de tempo, tendo vantagem tanto sobre o bagaço da cana-de-açúcar como sobre o eucalipto na produção de energia. Com a mesma quantidade, obtêm-se com o capim-elefante $84 \%$ mais energia do que com a cana e $37 \%$ mais do que com o eucalipto (VARGAS, 2010). Enquanto, eucalipto, árvore mais cultivada no Brasil para produzir celulose e carvão vegetal, em média, fornece 7,5 toneladas de biomassa seca por hectare ao ano, e até 20 toneladas, o capim produz de 30 a 40 toneladas (MAZZARELLA, 2007).

De fato, o ganho primário da utilização desta espécie e de outras poáceaes como fonte de energia alternativa é a própria potencialidade de acumulação de biomassa que estas espécies apresentam (DANALATOS et al., 2007; MONTI et al., 2007). Independentemente da forma de utilização pretendida, a elevada produtividade de biomassa é desejada, e algumas características morfológicas do capim-elefante são altamente correlacionadas com a produção de biomassa (XIA, 2010; DAHER et al., 2004). Portanto, faz-se necessário entender a dinâmica destas características durante o desenvolvimento das plantas para possibilitar a escolha de genótipos adequados para finalidades distintas.

O capim-elefante é uma das poáceaes mais exigentes em fertilidade do solo (NASCIMENTO JÚNIOR, 1981). Apesar da reconhecida importância da adubação fosfatada por ocasião do estabelecimento da pastagem, são escassos os trabalhos na literatura que evidenciam seu efeito residual sobre as produções dos anos subsequentes.

Outro elemento essencial é o nitrogênio na produtividade das poáceaes forrageiras, pois é responsável por características como o tamanho das folhas e dos colmos, e o aparecimento e o desenvolvimento dos perfilhos, fatores diretamente relacionados à produção de massa seca da planta forrageira (WERNER, 1986). É um nutriente que influencia sobre os processos envolvidos no crescimento e no desenvolvimento das plantas, alterando a relação fonte-dreno e, consequentemente, a distribuição de assimilados entre órgãos vegetativos e reprodutivos (PORTO et al., 2012).

A disponibilidade de nitrogênio é um dos fatores que controlam os processos de crescimento e desenvolvimento da planta, representado, sobretudo, pela maior rapidez de formação das gemas axilares e de iniciação dos perfilhos correspondentes. No entanto, esta iniciação só se manifesta enquanto o índice de área foliar não passa de um valor crítico, alterando a quantidade de luz que chega às gemas mais tardias (NABINGER \& MEDEIROS, 1995). Portanto, é fundamental $O$ desenvolvimento de trabalhos visando à determinação dos níveis críticos de fósforo e de nitrogênio no solo para a manutenção da produtividade desejada ao longo dos anos, garantindo maior longevidade da pastagem (MOREIRA, 2006).

É necessário manejo adequado dos fertilizantes, principalmente os nitrogenados, considerando a pobreza na disponibilidade deste nutriente no solo, fundamentalmente para obter ganhos de produtividade (FLORES et al., 2012).

Cultivares melhoradas de capim-elefante constituem-se em uma das mais importantes demandas dos produtores da região sul capixaba, tornando-se intensa a procura de variedades para produção de biomassa adaptadas aos diferentes ecossistemas e às condições edafoclimáticas. Sua inserção como fonte de energia renovável, do ponto de vista socioeconômico e ambiental, contribuirá significativamente no agronegócio, diminuindo os impactos ambientais provocados pelo uso predatório de florestas nativas, que têm causado danos ambientais, tais como acelerado assoreamento e consequente morte de diversos rios, uma vez que as derrubadas de árvores e a queima dos combustíveis fósseis têm sido a fonte de energia no fornecimento de calor utilizada em cerâmicas, olarias ou 
caldeiras na região.

Neste contexto, objetivou-se avaliar efeitos de doses de fósforo e de nitrogênio em cultivares de capim-elefante.

\section{Material e métodos}

O experimento foi instalado em área cultivável, com latitude de $20^{\circ} 45^{\prime} 57,9^{\prime \prime} \mathrm{S}$, longitude de $41^{\circ} 27^{\prime} 23,93^{\prime \prime}$ W e altitude de $126 \mathrm{~m}$, sendo essas informações obtidas pelo DATUM-SIRGAS 2000. O clima da região, segundo a classificação de Köppen, é do tipo Cwa, com estação seca no inverno, e verão quente e chuvoso. As condições meteorológicas observadas durante a condução do trabalho experimental estão descritas na Tabela 1.

Tabela 1 - Precipitação pluviométrica $(\mathrm{Pe})$, temperatura do ar, umidade relativa do ar (UR), evapotranspiração potencial diária $(E T P)$ e balanço hídrico $(\mathrm{BH})$ registrado no período de julho de 2012 a 14 de janeiro de 2013. Alegre-ES. Rainfall Precipitation (RP), Temperature $\left({ }^{\circ} \mathrm{C}\right)$, Relative Humidity (RH), Daily Potential Evapotranspiration (DPE) and Water Balance (WB) registered in the period from July/2012 to January/2013 in Alegre, ES.

\begin{tabular}{|c|c|c|c|c|c|c|c|c|}
\hline \multirow{2}{*}{ Mês/Ano } & \multirow{2}{*}{$^{\circ}=$ dias } & \multirow{2}{*}{$\begin{array}{c}\mathrm{Pe} \\
(\mathrm{mm})\end{array}$} & \multicolumn{3}{|c|}{ Temperatura do $\operatorname{ar}\left({ }^{\circ} \mathrm{C}\right)$} & \multirow{2}{*}{$\begin{array}{l}\text { UR } \\
(\%)\end{array}$} & \multirow{2}{*}{$\begin{array}{l}\text { ETP } \\
(\mathrm{mm})\end{array}$} & \multirow{2}{*}{$\frac{\mathrm{BH}}{(\mathrm{mm})}$} \\
\hline & & & Média & Máxima & Mínima & & & \\
\hline $07 / 2012$ & 2 & 7,70 & 20,90 & 28,80 & 15,00 & 71,00 & 3,20 & $-49,90$ \\
\hline $08 / 2012$ & 9 & 52,31 & 20,90 & 27,40 & 15,90 & 75,00 & 3,40 & $-53,09$ \\
\hline 09/2012 & 5 & 49,10 & 22,70 & 29,80 & 16,80 & 68,00 & 4,50 & $-85,90$ \\
\hline $10 / 2012$ & 3 & 30,50 & 25,30 & 32,80 & 19,00 & 63,00 & 5,60 & $-143,10$ \\
\hline $11 / 2012$ & 19 & 217,40 & 23,90 & 29,00 & 20,50 & 79,00 & 4,50 & 82,40 \\
\hline $12 / 2012$ & 4 & 33,90 & 27,80 & 35,30 & 22,50 & 69,00 & 6,30 & $-161,40$ \\
\hline $01 / 2013$ & 0 & 0,00 & 27,20 & 33,50 & 22,20 & 65,00 & 5,80 & $-81,40$ \\
\hline
\end{tabular}

Fonte: IFES_Campus de Alegre.

O solo foi amostrado na profundidade de 0-20 cm, para a caracterização da textura e de química do solo e apresentou 762,$5 ; 25,2$ e $212,3 \mathrm{~g} \mathrm{~kg}^{-1}$ de areia, silte e argila, respectivamente, $\mathrm{pH}\left(\mathrm{em} \mathrm{H}_{2} \mathrm{O}\right)$ de 6,$0 ; \mathrm{P}($ Mehlich 1) = $19,0 \mathrm{mg} \mathrm{dm}^{-3} ; \quad \mathrm{K}=67,0 \mathrm{mg} \mathrm{dm} ; \mathrm{Na}=$ $0,0 \mathrm{mg} \mathrm{dm}^{-3} ; \mathrm{Ca}=1,5 \mathrm{cmol} \mathrm{dm}^{-3} ; \mathrm{Mg}=$ $0,5 \mathrm{cmol} \mathrm{dm}^{-3} ; \mathrm{Al}=0,0 \mathrm{cmol} \mathrm{dm}^{-3} ; \mathrm{H}+\mathrm{Al}=$ $1,9 \mathrm{cmol} \mathrm{dm}^{-3}$; CTC(t) capacidade de troca catiônica efetiva $=2,2 \mathrm{cmol} \mathrm{dm}^{-3} ; \mathrm{CTC}(\mathrm{T})$ capacidade de troca catiônica a pH 7,0 $=4,2 \mathrm{cmol} \mathrm{dm}^{-3}$; S.B. $=2,2 \mathrm{cmol} \mathrm{dm}^{-3} ; \mathrm{V}=53,4 \% ; \mathrm{m}=0,0 \%$, realizada pelo Laboratório de Física do Solo, localizado no município de Alegre-ES. O solo foi classificado de acordo com a EMBRAPA (2006) como Latossolo Vermelho-Amarelo eutrófico.

Nesta área, foi conduzido um experimento não irrigado, em delineamento de blocos casualizados, no esquema de parcelas subsubdivididas. Foram avaliadas nas parcelas três cultivares (Guaçu/IZ.2, Cameroon-Piracicaba e Cana D'África) de capim-elefante, nas subparcela quatro doses de fósforo $\left(50 ; 100 ; 200\right.$ e $400 \mathrm{~kg} \mathrm{ha}^{-1}$ de $\left.\mathrm{P}_{2} \mathrm{O}_{5}\right)$ e nas subsubparcelas as cinco doses de nitrogênio $\left(0 ; 500 ; 1.000 ; 1.500\right.$ e $2.000 \mathrm{~kg} \mathrm{ha}^{-1} \mathrm{de}$ $\mathrm{N})$, com três repetições para cada tratamento.

A parcela foi composta de quatro linhas de plantio de $12,0 \mathrm{~m}$. A subparcela foi constituída de uma única linha de plantio, e esta foi fracionada em cinco partes iguais de 2,40 $\mathrm{m}$ de comprimento, constituindo a subsubparcela.

O plantio foi realizado em 22 de abril de 2010, em sulcos de $10,0 \mathrm{~cm}$ de profundidade, espaçados em 1,50 m. O fósforo, como fonte de superfosfato simples, foi incorporado ao solo do sulco. Em seguida, foram distribuídas as mudas, nos respectivos sulcos no sistema de pé com ponta, cortadas e cobertas a uma profundidade de $3,0 \mathrm{~cm}$. O nitrogênio (ureia) foi aplicado durante o ciclo vegetativo, em 21-08-2012, 14-09-2012, 13-10-2012, 04-11-2012 e 11-12-2012, em dias chuvosos, conforme a Tabela 1.

Foram feitos dois cortes de uniformização (4 de novembro de 2010) e o outro com 90 dias após o primeiro (fevereiro de 2011). Realizaram-se três cortes de avaliação. O primeiro corte, com 180, em agosto/setembro de 2011; o segundo corte, com 300, em julho de 2012, e o terceiro, com 180, dias em 15 de janeiro de 2013. Somente os dados obtidos no terceiro corte foram analisados. Para a obtenção da área útil de $1,50 \mathrm{~m}^{2}$, retirou-se $1,0 \mathrm{~m}$ de touceiras de cada subsubparcela. Foram medidos: diâmetro do colmo (DC), expresso em $\mathrm{mm}$, a $10 \mathrm{~cm}$ do nível do solo, através do uso de paquímetro digital, momentos antes do corte de avaliação; largura da lâmina foliar (LL), expressa em $\mathrm{cm}$, medida com régua milimetrada no terço médio da lâmina foliar, e a altura da planta (ALT), expressa em $\mathrm{m}$, medido com régua graduada em $\mathrm{cm}$, a partir do solo até o ápice das folhas eretas, momentos antes do corte para avaliação, baseando-se na altura de três plantas da área útil. Depois, foram pesadas as amostras de planta inteira e secas em estufa, a uma temperatura de $65^{\circ} \mathrm{C}$, sob circulação de ar forçada até atingir massa constante (ASA - amostra seca ao ar). Após a secagem, as amostras foram novamente pesadas, moídas em moinho tipo Wiley malha de $1 \mathrm{~mm}$ e acondicionadas em vidros. Os teores de 
matéria seca foram obtidos mediante secagem em estufa com ventilação de ar forçada, a $105^{\circ} \mathrm{C}$, por 24 horas (ASE - amostra seca em estufa), servindo este parâmetro para expressar a produção de matéria seca (PMS) em $t \mathrm{ha}^{-1}$, esta estimada pelo produto do peso da matéria verde das plantas inteiras $(\mathrm{kg})$, obtido em balança digital, provenientes de 1,5 metro quadrado $\left(1,5 \mathrm{~m}^{2}\right)$, e pela percentagem de matéria seca da planta integral (\%MS), o valor obtido (kg $\mathrm{m}^{-2}$ ) foi convertido para t ha ${ }^{-1}$. A percentagem de matéria seca (\%MS) foi estimada em amostras de plantas inteiras extraídas aleatoriamente dentre as plantas cortadas da área útil, pesadas e submetidas à pré-secagem e pesadas novamente, realizada de acordo com a metodologia descrita por SILVA \& QUEIROZ (2002). O número de perfilhos por metro (NPPM) foi obtido pela contagem do número de perfilhos com altura superior a $70 \mathrm{~cm}$, oriundos da área útil da subsubparcela, momentos antes do corte de avaliação.

Os dados obtidos no terceiro corte, referentes ao período de 15 de julho de 2012 a 15 de janeiro de 2013, foram submetidos à análise estatística no modelo de parcelas subsubdivididas no espaço, utilizando o Software SAEG para verificar a significância dos fatores e a interação genótipos $x$ tratamentos, aplicando o teste de Tukey a 5\%. Havendo efeito significativo, foi realizado o estudo de regressão polinomial para doses de nitrogênio e fósforo para cada cultivar.

O modelo de delineamento estatístico utilizado foi o de blocos ao acaso, no esquema de parcelas subsubdivididas, por meio do software SAEG versão 9.0, considerando o efeito principal de genótipo (clones) e os efeitos secundários de blocos, dos níveis de fósforo e nitrogênio descrito a seguir:

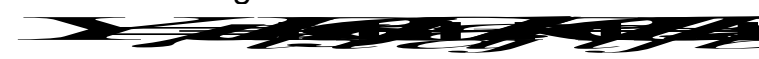
, em que:

$Y_{i j k l}=$ valor observado relativo ao i-ésimo genótipo, no j-ésimo fósforo, no k-ésimo nitrogênio e no l-ésimo bloco; $\mu=$ média geral do ensaio; $\mathbf{G}_{\mathbf{i}}=$ efeito do i-ésimo genótipo; $\boldsymbol{B}_{l}=$ efeito do l-ésimo bloco; $\varepsilon_{\mathrm{a}}=$ efeito do erro a associado ao i-ésimo genótipo no l-ésimo bloco; $\boldsymbol{P}_{j}=$ efeito do j-ésimo fósforo; $\boldsymbol{G}_{i} \boldsymbol{P}_{j}=$ efeito da interação do i-ésimo genótipo com o j-ésimo fósforo; $\varepsilon_{\mathrm{b}}=$ efeito do erro $\mathrm{b}$ associado ao $\mathrm{i}$ -ésimo genótipo ao j-ésimo fósforo no l-ésimo bloco; $N_{k}=$ efeito do k-ésimo nitrogênio; $G_{i} N_{k}=$ efeito da interação do i-ésimo genótipo com k-ésimo nitrogênio; $P_{j} N_{k}=$ efeito da interação do j-ésimo fósforo com k-ésimo nitrogênio; $\boldsymbol{G}_{i} \boldsymbol{P}_{j} \boldsymbol{N}_{\boldsymbol{k}}=$ efeito da interação do j-ésimo genótipo com J-ésimo fósforo e k-ésimo nitrogênio; $\varepsilon_{c}=$ efeito do erro c associado ao iésimo genótipo ao j-ésimo fósforo e k-ésimo nitrogênio no l-ésimo bloco.

$$
\varepsilon_{\mathrm{a}}, \varepsilon_{\mathrm{b}} \text { e } \varepsilon_{\mathrm{c}} \sim \operatorname{NID}\left(0, \sigma_{\varepsilon_{\mathrm{a}, \mathrm{b}, \mathrm{c}}}^{2}\right)
$$

\section{Resultados e discussão}

Os resultados das análises de variância simples para as características morfoagronômicas avaliadas envolvendo três genótipos sob quatro doses de fósforo e cinco de nitrogênio evidenciaram efeito não significativo $(P>0,05)$ pelo teste $F$ para todas as características morfoagronômicas nas fontes de variação do fator fósforo, e das interações que envolvem esse fator, indicando independência entre os fatores. Para as fontes de variação genótipo, não houve efeito significativo $(P>0,05)$ para $P M S, \% M S$ e $\mathrm{LL}$, e para o fator nitrogênio, as características DC e LL. Entretanto, houve efeito significativo $(P<0,01)$ para nitrogênio nas características PMS, NPPM e ALT, e em \%MS $(P<0,05)$. O fator genótipo influenciou significativamente, a ALT $(P<0,05)$ e DC e NPPM $(P<0,01)$. Assim, observou-se que a adubação nitrogenada, não influenciou no DC e na LL do capim-elefante.

Observou-se que, para as características morfoagronômicas (Tabela 2), as características PMS e ALT referentes às três cultivares não diferiram entre si, estatisticamente, quanto às doses de N.

A produção de matéria seca de 'Guaçu/I.Z.2' difere da obtida por ANDRADE et al. (2000), com um intervalo de corte de seis meses. Estes autores obtiveram um total anual de $49,48 \mathrm{t} \mathrm{ha}^{-1}$ e de $30,91 \mathrm{t} \mathrm{ha}^{-1}$ nos experimentos realizados nos municípios paulistas de Brotas e Odessa, respectivamente, mesmo utilizando

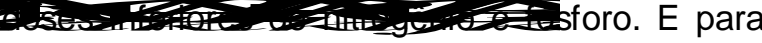
'Cameroon- Piracicaba', os resultados diferem dos de MORAIS et al. (2009), obtidos em três ciclos, para o mesmo genótipo, utilizando a adubação nitrogenada inferior. A cv. Cameroon produziu, no $3^{\circ}$ ciclo, 8,17 t ha $^{-1}$ em 18 meses, em Ponta Ubu, Anchieta-ES. E Botrel et al. (2000), estudando novos clones de capim-elefante, dentre os quais Cameroon, encontraram produtividade média anual de $31 \mathrm{t} \mathrm{ha}^{-1} \mathrm{ano}^{-1}$.

A época de crescimento e desenvolvimento dessa coleta foi, em sua maioria, no período de baixa precipitação pluviométrica, de $390,95 \mathrm{~mm}$, o que pode explicar essas baixas produtividades, além de existir um decréscimo na produtividade de matéria seca das espécies ao longo dos cortes (SANTOS et al., 2003). Levando em consideração a condição de estresse citada anteriormente, pode ter influenciado na menor produtividade observada para 'Guaçu/I.Z.2', devido a uma provável menor 
resistência desta cultivar às mudanças climáticas que ocorrem em condições de climas tropicais. A resposta de 'Cameroon-Piracicaba' pode ser considerada promissora, levando em consideração a significativa falta de chuvas no segundo semestre de 2012, cuja precipitação pluviométrica foi de $390,95 \mathrm{~mm}$. De acordo com QUESADA et al. (2004), essa cultivar possui elevadas produções de biomassa, principalmente na época seca, além de apresentar também ele- vados teores de fibras.

Em se tratando do NPPM, as cultivares não diferiram estatisticamente nas doses 0 ; 1.000 e $2.000 \mathrm{~kg} \mathrm{ha}^{-1}$ de $\mathrm{N}$, enquanto na dose 500 e $1.500 \mathrm{~kg} \mathrm{ha}^{-1}$ de N, 'Cameroon-Piracicaba' apresentou 22,08 e 23,67 NPPM, respectivamente, e por ter perfilhado menos, diferiu estatisticamente de 'Guaçu/IZ.2' e 'Cana D'África', que apresentaram 29,58 e 30,92, e 31 e 34 NPPM, respectivamente.

Tabela 2 - Valores médios das características morfoagronômicas avaliadas em três cultivares de capim-elefante sob diferentes doses de $\mathrm{N}\left(0 ; 500 ; 1.000 ; 1.500\right.$ e $2.000 \mathrm{~kg} \mathrm{ha}^{-1}$ de $\left.\mathrm{N}\right)$ num intervalo de tempo de 180 dias, para fins energéticos, no município de Alegre-ES, 2012-2013. Average values of morphoagronomic characteristics evaluated in three cultivars of elephant grass under different levels of nitrogen $(0,500,1000,1500$ and $2000 \mathrm{~kg}$ ha-1 N) in a time interval of 180 days, for energy purposes in Alegre-ES, 2012-2013.

\begin{tabular}{|c|c|c|c|c|c|}
\hline \multirow[b]{2}{*}{ PMS } & \multicolumn{5}{|c|}{${ }^{(1)}$ Características Morfoagronômicas } \\
\hline & \multicolumn{5}{|c|}{ Doses de nitrogênio $\left(\mathrm{kg} \mathrm{ha}^{-1}\right)$} \\
\hline Genótipos & 0 & 500 & 1000 & 1500 & 2000 \\
\hline Guaçu/IZ.2 & $14,16 \mathrm{a}$ & $15,54 \mathrm{a}$ & $15,27 \mathrm{a}$ & $14,86 \mathrm{a}$ & $12,53 \mathrm{a}$ \\
\hline Cameroon & $13,23 \mathrm{a}$ & $14,70 \mathrm{a}$ & $15,60 \mathrm{a}$ & 15,29 a & $13,38 \mathrm{a}$ \\
\hline Cana-D’África & $11,51 \mathrm{a}$ & $15,64 \mathrm{a}$ & $15,78 \mathrm{a}$ & $15,31 \mathrm{a}$ & $11,76 \mathrm{a}$ \\
\hline $\mathrm{DC}$ & \multicolumn{5}{|c|}{ Doses de nitrogênio(kg ha $\left.{ }^{-1}\right)$} \\
\hline Genótipos & 0 & 500 & 1000 & 1500 & 2000 \\
\hline Guaçu/IZ.2 & $1,54 \mathrm{~b}$ & $1,57 b$ & $1,51 \mathrm{~b}$ & $1,56 \mathrm{~b}$ & $1,51 \mathrm{~b}$ \\
\hline Cameroon & $1,80 \mathrm{a}$ & $1,86 \mathrm{a}$ & $1,82 \mathrm{a}$ & $1,92 \mathrm{a}$ & $1,79 \mathrm{a}$ \\
\hline Cana-D'África & $1,56 \mathrm{~b}$ & $1,52 \mathrm{~b}$ & $1,53 \mathrm{~b}$ & $1,57 \mathrm{~b}$ & $1,55 \mathrm{~b}$ \\
\hline NPPM & \multicolumn{5}{|c|}{ Doses de nitrogênio(kg ha $\left.{ }^{-1}\right)$} \\
\hline Genótipos & 0 & 500 & 1000 & 1500 & 2000 \\
\hline Guaçu/IZ.2 & $27,83 \mathrm{a}$ & $29,58 \mathrm{a}$ & $30,67 \mathrm{a}$ & $31,00 \mathrm{a}$ & $26,75 \mathrm{a}$ \\
\hline Cameroon & $22,33 \mathrm{a}$ & $22,08 \mathrm{~b}$ & $26,08 \mathrm{a}$ & $23,67 \mathrm{~b}$ & $24,50 \mathrm{a}$ \\
\hline Cana-D’África & $23,67 \mathrm{a}$ & $30,92 \mathrm{a}$ & $30,67 \mathrm{a}$ & $34,00 \mathrm{a}$ & 27,25 a \\
\hline $\mathrm{ALT}$ & \multicolumn{5}{|c|}{ Doses de nitrogênio $\left(\mathrm{kg} \mathrm{ha}^{-1}\right)$} \\
\hline Genótipos & 0 & 500 & 1000 & 1500 & 2000 \\
\hline Guaçu/IZ.2 & $274,58 \mathrm{a}$ & $272,08 \mathrm{a}$ & $272,08 \mathrm{a}$ & $278,33 \mathrm{a}$ & $268,33 \mathrm{a}$ \\
\hline Cameroon & $275,83 a$ & $280,42 \mathrm{a}$ & $280,83 \mathrm{a}$ & 291,67 a & $276,25 \mathrm{a}$ \\
\hline Cana-D’África & $277,50 \mathrm{a}$ & $275,00 \mathrm{a}$ & $274,17 \mathrm{a}$ & $285,83 a$ & $268,33 \mathrm{a}$ \\
\hline $\mathrm{LL}$ & \multicolumn{5}{|c|}{ Doses de nitrogênio(kg ha $\left.{ }^{-1}\right)$} \\
\hline Genótipos & 0 & 500 & 1000 & 1500 & 2000 \\
\hline Guaçu/IZ.2 & $5,81 \mathrm{a}$ & $5,70 a b$ & $5,85 \mathrm{a}$ & $5,54 \mathrm{~b}$ & $5,50 \mathrm{a}$ \\
\hline Cameroon & $5,63 a b$ & 5,93 a & 5,95 a & 6,16 a & $5,85 a$ \\
\hline Cana-D’África & $5,32 \mathrm{~b}$ & $5,40 \mathrm{~b}$ & $5,59 a$ & $5,72 b$ & $5,72 \mathrm{a}$ \\
\hline \multicolumn{6}{|c|}{$\begin{array}{l}\text { (1) Médias seguidas pela mesma letra minúscula na vertical não diferem estatisticamente entre si, pelo teste de } \\
\text { Tukey, ao nível de } 5 \% \text { de probabilidade; PMS - Produção de matéria seca integral da planta, em t ha }{ }^{-1} \text {; \% } \% \text { - } \\
\text { Percentagem de matéria seca integral; DC - Diâmetro médio de colmo em milímetros; NPPM - Número de } \\
\text { perfilhos por metro linear; ALT - Altura média da planta em metros; LL - Largura média da lâmina foliar em } \\
\text { centímetros. }{ }^{(1)} \text { Means followed by the same lower case letter in vertical are not statistically different among them } \\
\text { by Tukey test with a probability of } 5 \% \text {; PMS - Full dry matter production of plant in } \text { ha }^{-1} ; \% M S \text { - Percentage of full } \\
\text { dry matter; DC - mean stem diameter in millimeters, NPPM - number of tillers per meter, ALT - mean plant height } \\
\text { in meters, LL - mean leaf blade width in centimeters.. }\end{array}$} \\
\hline
\end{tabular}

A cv. Cana-D'África respondeu positivamente ao incremento de $\mathrm{N}$, sobressaindo-se em perfilhamento com 30,92 e 34 NPPM em relação à 'Cameroon-Piracicaba', diferindo estatisticamente desta cultivar nas doses de 500 e $1.500 \mathrm{~kg} \mathrm{ha}^{-1}$ de $\mathrm{N}$, em virtude de ter apresentado maior número de perfilhos nessas doses do que nas doses de 0 e $2.000 \mathrm{~kg} \mathrm{ha}^{-1}$ de $\mathrm{N}$.

Com relação ao diâmetro do colmo (DC), somente a cv. Cameroon-Piracicaba diferiu estatisticamente das demais, sobressaindo-se em relação à 'Guaçu/IZ.2' e 'Cana-D’África' em todas as doses de nitrogênio utilizadas, com os respectivos valores 1,$80 ; 1,86 ; 1,82 ; 1,92$ e $1,79 \mathrm{~cm}$. 
O diâmetro do colmo (DC) da cv. CameroonPiracicaba oscilou em diferentes doses de nitrogênio.

Analisando os valores do DC, a cultivar Cameroon-Piracicaba apresentou maiores valores, e os menores a cv. Guaçu/IZ.2, nas doses 0; 1.000; 1.500 e $2.000 \mathrm{~kg} \mathrm{ha}^{-1}$ de N, e a cultivar CanaD'África o menor valor foi manifestado na dose de $500 \mathrm{~kg} \mathrm{ha}^{-1}$ de N. No entanto, na relação do DC com a PMS, pode-se observar que a maior PMS ocorreu com a cv. Cana-D'África nas doses de 500; 1.000 e $1.500 \mathrm{~kg} \mathrm{ha}^{-1}$, com destaque na dose de $500 \mathrm{~kg} \mathrm{ha}^{-1}$, mesmo apresentando o menor DC. Esse comportamento pode não estar diretamente ligado com o efeito da adubação nitrogenada e, sim, com as condições ambientais ideais ao bom desempenho desta cultivar, pois o número de perfilhos de uma cultivar tende a aumentar com intervalos de corte mais prolongados. Isso ocorre porque, com o avançar da idade, ocorre a maturidade fisiológica das plantas, verificando-se aumento na espessura das paredes das células vegetais e, consequentemente, um aumento no DC, que proporciona às plantas a estabilidade estrutural (VEIGA, 1997).

Os valores de DC oscilaram de $15,10 \mathrm{~mm}$ a 19,24 mm, obtendo a média geral de $17,41 \mathrm{~mm}$. DAHER et al. (2000) também encontraram valores semelhantes para diâmetro médio. PEREIRA et al. (2006) encontraram valores próximos, obtendo a média de $10,8 \mathrm{~mm}$ de diâmetro do colmo, indicando considerável amplitude de variação por ser uma característica de alta variabilidade entre os acessos avaliados.

Segundo MELLO et al. (2002), o diâmetro de colmo relaciona-se diretamente com a tolerância da planta ao período seco, ou seja, colmos de maior diâmetro são também mais tolerantes à seca, provavelmente devido ao maior conteúdo de compostos de reserva nesses materiais (SILVA, 2010).

Para a característica LL, as cultivares Guaçu/IZ.2 e Cana-D'África diferiram estatisticamente de 'Cameroon-Piracicaba' na dose de $1.500 \mathrm{~kg} \mathrm{ha}^{-1}$ de $\mathrm{N}$, por terem apresentado menor largura de lâmina, cujos respectivos valores foram de 5,54 e 5,71cm, enquanto 'Cameroon-Piracicaba' foi de $6,16 \mathrm{~cm}$. A cv. Cana-D'África diferiu de 'Guaçu/IZ.2' somente na dose zero, mas não diferiu de 'Cameroon- Piracicaba' nessa dose, cujos respectivos valores foram de 5,32; 5,81 e $5,63 \mathrm{~cm}$. Já na dose de $500 \mathrm{~kg} \mathrm{ha}^{-1}$ de $\mathrm{N}$, a cultivar Cana-D'África com $5,93 \mathrm{~cm}$ de LL diferiu de 'Cameroon-Piracicaba' e não diferiu de 'Guaçu/IZ.2'. Entretanto, 'Cameroon-Piracicaba' respondeu positivamente ao incremento de $\mathrm{N}$, aumentando a LL nas doses de 500 e $1.500 \mathrm{~kg}$ $\mathrm{ha}^{-1}$ de N, apresentando 5,93 e $6,16 \mathrm{~cm}$ de LL, respectivamente, diferindo estatisticamente de 'Cana-D'África' nessas doses, e de 'Guaçu/IZ.2' na dose de $1.500 \mathrm{~kg} \mathrm{ha}^{-1}$ de $\mathrm{N}$.

$O$ efeito da adubação nitrogenada em capim-elefante é considerável na produção de matéria seca e proteína bruta segundo MORAIS (2008), e verifica-se um aumento de produção de matéria seca à medida que se aumenta a dose de nitrogênio aplicado (CORSI, 1972; WERNER, 1984), com exceção das características diâmetro do colmo, largura da lâmina e número de perfilhos por metro, que são características genotípicas das cultivares. O número de perfilhos por metro é uma característica de alta herdabilidade, possibilitando sua transferência em programas de melhoramento da espécie (SILVA et al., 2010).

DAHER et al. (2004) concluíram que esta variável foi capaz de explicar melhor o potencial de produção de matéria seca, atuando de forma direta na variável básica. No entanto, na relação do diâmetro do colmo com a produção de matéria seca, pode-se observar que existe uma relação inversa de 'Cameroon-Piracicaba' e 'Guaçu/IZ.2' nas doses de 0 e $500 \mathrm{~kg} \mathrm{ha}^{-1}$ de $\mathrm{N}$, e de 'Cameroon-Piracicaba' e 'Cana-D'África' nas doses de $500 ; 1.000$ e $1.500 \mathrm{~kg} \mathrm{ha}^{-1}$ de N. E também verificaram correlação inversa entre as características diâmetro do colmo e produção de matéria seca, segundo os autores, por conta das condições ambientais em que as plantas se desenvolveram. Já na dose de $2.000 \mathrm{~kg} \mathrm{ha}^{-1}$ de $\mathrm{N}$, 'Cameroon-Piracicaba' apresentou maior diâmetro do colmo e foi o que manifestou melhor resposta na produção de matéria seca, demonstrando uma correlação diretamente positiva entre essas variáveis.

Os modelos polinomiais mais representativos ( $1^{\circ}$ grau, $2^{\circ}$ grau ou ausência de regressão) das três cultivares pesquisadas estão representados na Tabela 3.

Analisando a produção de matéria seca obtida em t ha ${ }^{-1}$ no $3^{\circ}$ corte (PMS), as cultivares não diferiram estatisticamente pelo teste de Tukey, a $5 \%$ de probabilidade, nas doses utilizadas. Porém, pela análise de regressão, pode-se verificar que as cultivares que demonstraram modelo significativo e altamente significativo para regressão de $2^{\circ} \mathrm{grau}$, foram as cvs. Guaçu/IZ.2 e Capim-CanaD'África, as quais apresentaram coeficientes de determinação de $R^{2}=97,17 \%$ e $R^{2}=96,96 \%$, respectivamente. Contudo, para 'Cameroon-Piracicaba', os modelos obtidos de $1^{\circ}$ e $2^{\circ}$ graus não se ajustaram à significância de $5 \%$ pelo teste $\mathrm{F}$. O modelo que melhor se ajustou para 'CameroonPiracicaba' a 5,9 \% de significância foi o de 20 grau, apresentando um $R^{2}=97,76 \%$.

As estimativas de quadrados médios para as fontes, devido à regressão e aos desvios de regressão envolvendo três cultivares de capim-elefante referentes ao $3^{\circ}$ corte encontram-se na Tabela 3. 
Tabela 3 - Modelos polinomiais de $1^{\circ}$ e de $2^{\circ}$ graus para as características morfoagronômicas de três cultivares (Guaçu/IZ.2, Cameroon-Piracicaba e Cana-D'África), sob 5 doses de nitrogênio $(0 ; 500 ; 1.000$; 1.500 e $2.000 \mathrm{~kg} \mathrm{ha}^{-1} \mathrm{de} \mathrm{N}$ ), em Alegre-ES, 2012-2013. $1^{\text {st }}$ and $2^{\text {nd }}$ polynomial model of the morphoagronomic characteristics of three cultivars (Guaçu/IZ.2, Cameroon-Piracicaba and Cana D'África) under five nitrogen doses (0,500, 1000, 1500 and 2000 models $\mathrm{kg} \mathrm{ha}^{-1}$ of N) in Alegre-ES, 2012-2013.

\begin{tabular}{|c|c|c|c|}
\hline \multirow[b]{2}{*}{ PMS } & \multicolumn{3}{|c|}{ Características Morfoagronômicas } \\
\hline & Modelo & Equação de Regressão & $\mathrm{R}^{2}$ \\
\hline Guaçu/IZ.2 & 2 & $\hat{y}=14,1781+3,53 \times 10^{-3} \mathrm{~N}-2,16 \times 10^{-6} \mathrm{~N}^{2}$ & $97,17 \%$ \\
\hline Cameroon & 2 & $\hat{y}=13,1201+4,74 \times 10^{-3} \mathrm{~N}-2,28 \times 10^{-6} \mathrm{~N}^{2}$ & $97,76 \%$ \\
\hline Cana-D’África & 2 & $\hat{y}=11,6853+9,16 \times 10^{-3} \mathrm{~N}-4,56 \times 10^{-6} \mathrm{~N}^{2}$ & $96,96 \%$ \\
\hline $\mathrm{DC}$ & Modelo & Equação de Regressão & $\mathrm{R}^{2}$ \\
\hline Guaçu/IZ.2 & Ausência & $\hat{y}=1,5373$ & \\
\hline Cameroon & Ausência & $\hat{y}=1,8405$ & \\
\hline Cana-D’África & Ausência & $\hat{y}=1,5475$ & \\
\hline NPPM & Modelo & Equação de Regressão & $\mathrm{R}^{2}$ \\
\hline Guaçu/IZ.2 & Ausência & $\hat{y}=29,1666$ & \\
\hline Cameroon & Ausência & $\hat{y}=123,7333$ & \\
\hline Cana-D’África & 2 & $\hat{y}=23,7619+1,6 \times 10^{-2} N-6,98 \times 10^{-6} N^{2}$ & $84,93 \%$ \\
\hline ALT & Modelo & Equação de Regressão & $\mathrm{R}^{2}$ \\
\hline Guaçu/IZ.2 & Ausência & $\hat{y}=2,73$ & \\
\hline Cameroon & Ausência & $\hat{y}=2,81$ & \\
\hline Cana-D’África & Ausência & $\hat{y}=2,76$ & \\
\hline LL & Modelo & Equação de Regressão & $\mathrm{R}^{2}$ \\
\hline Guaçu/IZ.2 & Ausência & $\hat{y}=5,6803$ & \\
\hline Cameroon & 2 & $\hat{y}=5,6260+7,18 \times 10^{-4} N-2,9 \times 10^{-7} N^{2}$ & $82,00 \%$ \\
\hline Cana-D’África & 1 & $\hat{y}=5,3277+2,23 \times 10^{-4} \mathrm{~N}$ & $93,54 \%$ \\
\hline
\end{tabular}

Produção de matéria seca integral da planta em $\mathrm{tha}^{-1}=\mathrm{PMS}$; Percentagem de matéria seca integral $=\% \mathrm{MS}$; Diâmetro médio de colmo em milímetros = DC; Número de perfilhos por metro linear = NPPM; Altura média da planta em metros $=\mathrm{ALT}$; Largura média da lâmina foliar em centímetros $=\mathrm{LL}$. Full production of plant dry matter in tha-1 = PMS; Percentage of full MS =\% dry matter, mean stem diameter in millimeters $=D C$, number of tillers per meter $=$ NPPM, mean plant height in meters $=A L T$, the leaf blade in feet $L L=$ average width .

Todas as três cultivares (Guaçu/IZ.2, Cameroon-Piracicaba e Cana-D’África), quanto à produção obtida de matéria seca (PMS), apresentaram ajuste significativo de equação de segundo grau, tornando possível a determinação do máximo físico e a utilização da função de produção para mensurar o ótimo econômico e a produtividade ótima (Figura 1).

As máximas produtividades de matéria seca estimadas foram de $15,62 \mathrm{t} \mathrm{ha}^{-1}$, para 'Guaçu/IZ.2', na dosagem de $817,13 \mathrm{~kg} \mathrm{ha}^{-1}$ de $\mathrm{N}, 15,59 \mathrm{t} \mathrm{ha}^{-1}$ de 'Cameroon- Piracicaba' com $1.039,47 \mathrm{~kg} \mathrm{ha}^{-1}$ de $\mathrm{N}$ e 16,29 $\mathrm{t} \mathrm{ha}^{-1}$ de 'Cana-D'África' com $1.004,43 \mathrm{~kg} \mathrm{ha}^{-1}$ de N.

Com $2.000 \mathrm{~kg} \mathrm{ha}^{-1}$ de $\mathrm{N}$, causou diminuição na produção de matéria seca da cv. Cameroon-Piracicaba, atingindo 13,39 $\mathrm{t} \mathrm{ha}^{-1}$, equivalente à produção sem adubação nitrogenada de 13,23 t ha ${ }^{-1}$. Esses resultados divergiram dos resultados obtidos por MORAIS et al. (2009), para a mesma cultivar, e utilizando a dose de $\mathrm{N}$ inferior. Os autores verificaram que a cv. Cameroon produziu, no $3^{\circ}$ ciclo, $8,17 \mathrm{t} \mathrm{ha}^{-1}$ em 18 meses em Ponta Ubu, Anchieta-ES. BOTREL et al. (2000), estudando novos clones de capim-elefante, dentre eles 'Cameroon', encontraram produtividade média anual de $31 \mathrm{t} \mathrm{ha}^{-1} \mathrm{ano}^{-1}$ de matéria seca.

OLIVEIRA (2012) observou que na Produção de Matéria Seca (PMS), pela análise de regressão, a cultivar Cameroon-Piracicaba respondeu linearmente ao aumento do fornecimento de $\mathrm{N}$ até $1.600 \mathrm{~kg} \mathrm{ha}^{-1}$ de $\mathrm{N}$, indicando que existe necessidade de maior adubação nitrogenada, para se obter melhor resposta de matéria seca.

Segundo VITOR et al. (2009), a produção de matéria seca acumulada aumenta linearmente de acordo com as doses de nitrogênio $(100,300$, 500 e $700 \mathrm{~kg} \mathrm{ha}^{-1}$ de N), para o capim-elefante cv. Napier com as lâminas d'água aplicadas durante todo o período experimental e o período chuvoso, enquanto no período seco, os resultados da produção de matéria seca do capim-elefante ajustaram-se ao modelo quadrático de regressão com as lâminas d'água aplicadas. A maior produção acumulada em todos os períodos foi obtida com a dose de nitrogênio de $700 \mathrm{~kg} \mathrm{ha}^{-1}$, $29.049,04 \mathrm{~kg} \mathrm{ha}^{-1}$ de matéria em todo o período experimental, sendo $21.128,43 \mathrm{~kg} \mathrm{ha}^{-1}$ no período chuvoso e $8.066,73 \mathrm{~kg} \mathrm{ha}^{-1}$ de matéria seca no período seco, em um experimento irrigado, cujo 
período foi de 7 de outubro de 2003 a 6 de janeiro de 2005, realizado no Campo Experimental de Coronel Pacheco (MG) pertencente à Embrapa Gado de Leite.

A cv. Cana-D'África respondeu positivamente ao incremento das doses de $\mathrm{N}$, até atingir o máximo físico de $1.004,43 \mathrm{~kg} \mathrm{ha}^{-1}$ de $\mathrm{N}$, obtendo assim a produtividade máxima estimada de 16,29 t ha-1 ( Figura 1), mas não diferiu estatisticamente das demais cultivares.

A cv. Cana-D'África apresentou modelo polinomial significativo a $1 \%$, pelo teste $\mathrm{F}$, na característica NPPM. O modelo que melhor se ajustou foi 0 de $2^{\circ}$ grau, com $R^{2}=84,93 \%$, conforme a representação da Figura 2.

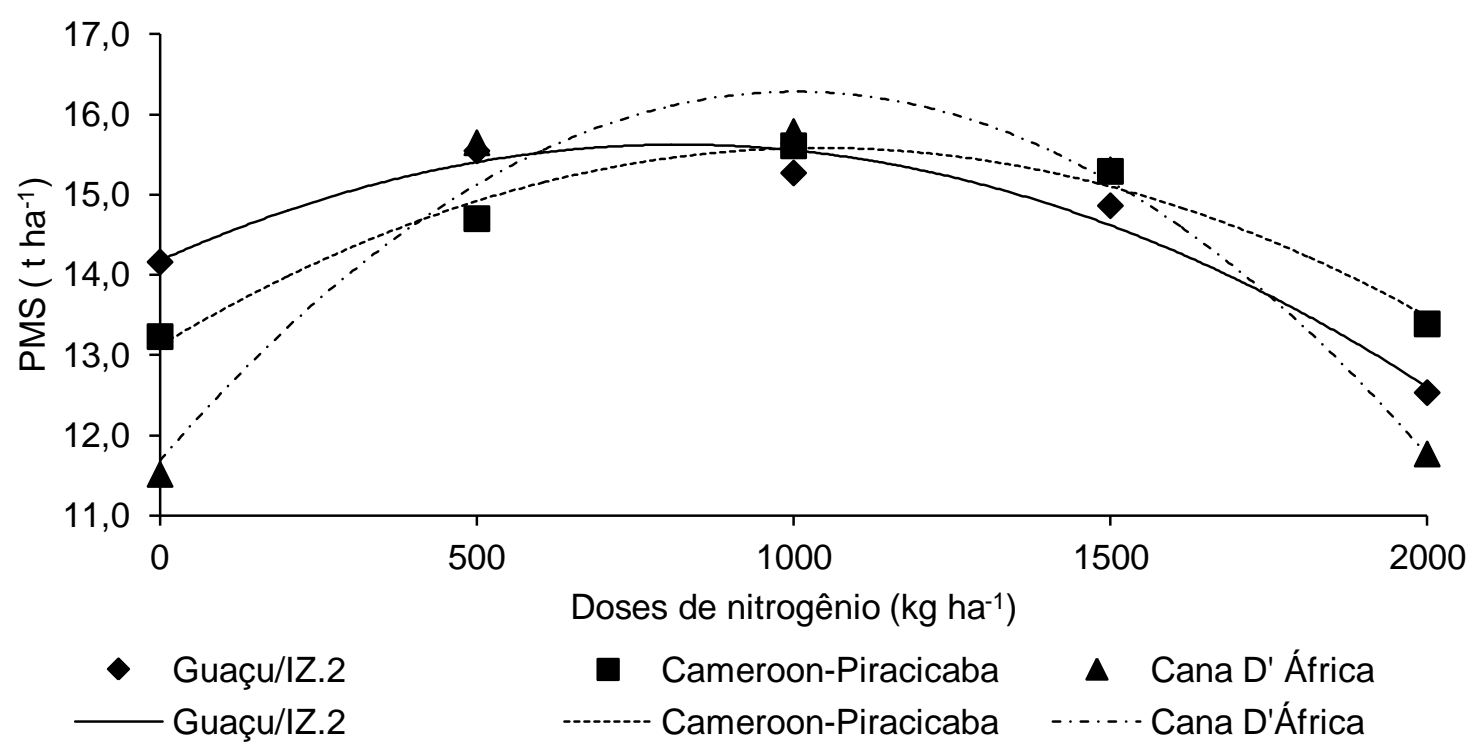

Figura 1 - Produção de matéria seca (PMS) de cultivares de capim-elefante em função de doses de nitrogênio. Dry Matter Production (DMP) of elephant grass cultivars as function of nitrogen rates.

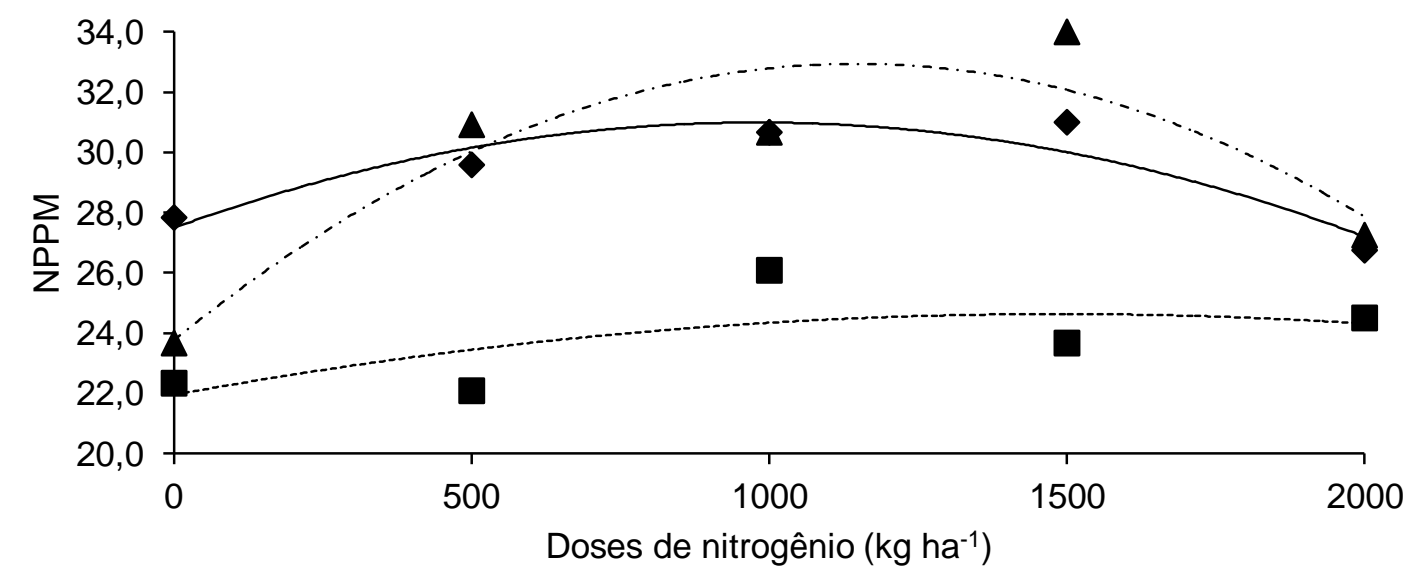
- Guaçu/IZ.2
- Cameroon-Piracicaba
$\Delta$ Cana D' África
- Guaçu/IZ.2
Cameroon-Piracicaba
-..... Cana D'África

Figura 2 - Número de plantas por metro (NPPM) de cultivares de capim-elefante em função de doses de nitrogênio. Number of Plants per Meter (NPPM) of elephant grass cultivars as function of nitrogen rates.

A cv. Cameroon-Piracicaba demonstrou menor perfilhamento em todas as doses de $\mathrm{N}$ utilizadas, mas somente nas doses de 500 e
$1.500 \mathrm{~kg} \mathrm{ha}^{-1}$ de $\mathrm{N}$ diferiu estatisticamente das demais, em virtude da resposta positiva ao incremento de $\mathrm{N}$ que 'Cana-D'África' manifestou 
até o limite em que o $\mathrm{N}$ deprimiu essa característica (NPPM) de $1.146,13 \mathrm{~kg} \mathrm{ha}^{-1}$ de $\mathrm{N}$, atingindo um perfilhamento máximo estimado de 33 plantas $\mathrm{m}^{-1}$. Entretanto, essa cultivar demonstrou pequena diminuição no perfilhamento na dose $1.000 \mathrm{~kg} \mathrm{ha}^{-1}$ de $\mathrm{N}$, mas na dose de $1.500 \mathrm{~kg} \mathrm{ha}^{-1}$ de $\mathrm{N}$ aumentou o perfilhamento, alcançando 34 plantas por metro, e 'Guaçu/IZ.2', na dose $1.500 \mathrm{~kg} \mathrm{ha}^{-1}$ de $\mathrm{N}$, alcançou 31 plantas $\mathrm{m}^{-1}$, enquanto OLIVEIRA (2012), pela análise de regressão do Número de Plantas (NP), verificou que a única cultivar que demonstrou regressão foi 'Cameroon-Piracicaba', com $\mathrm{R}^{2}=90,36 \%$, ao nível de significância de $1 \%$ pelo teste $\mathrm{F}$, e o modelo de melhor ajuste foi o de $1^{\circ}$ grau. Assim, essa tendência de regressão de $1^{\circ}$ grau indica que existe necessidade de maior adubação nitrogenada para se obter melhor resposta em nível de perfilhos.

A característica largura média da lâmina foliar (LL) demonstrou ausência de regressão para 'Guaçu/IZ.2', e para 'Cameroon-Piracicaba' e 'Cana-D'Äfrica', os modelos que melhor se ajustaram, foram o de $2^{\circ}$ grau, ao nível de $5 \%$ de significância, pelo teste $F$, e o de $1^{\circ}$ grau, ao nível de $1 \%$ de significância, com os respectivos coeficientes de determinação $R^{2}=82,00 \%$ e 93,54\%, conforme a representação da Figura 3.
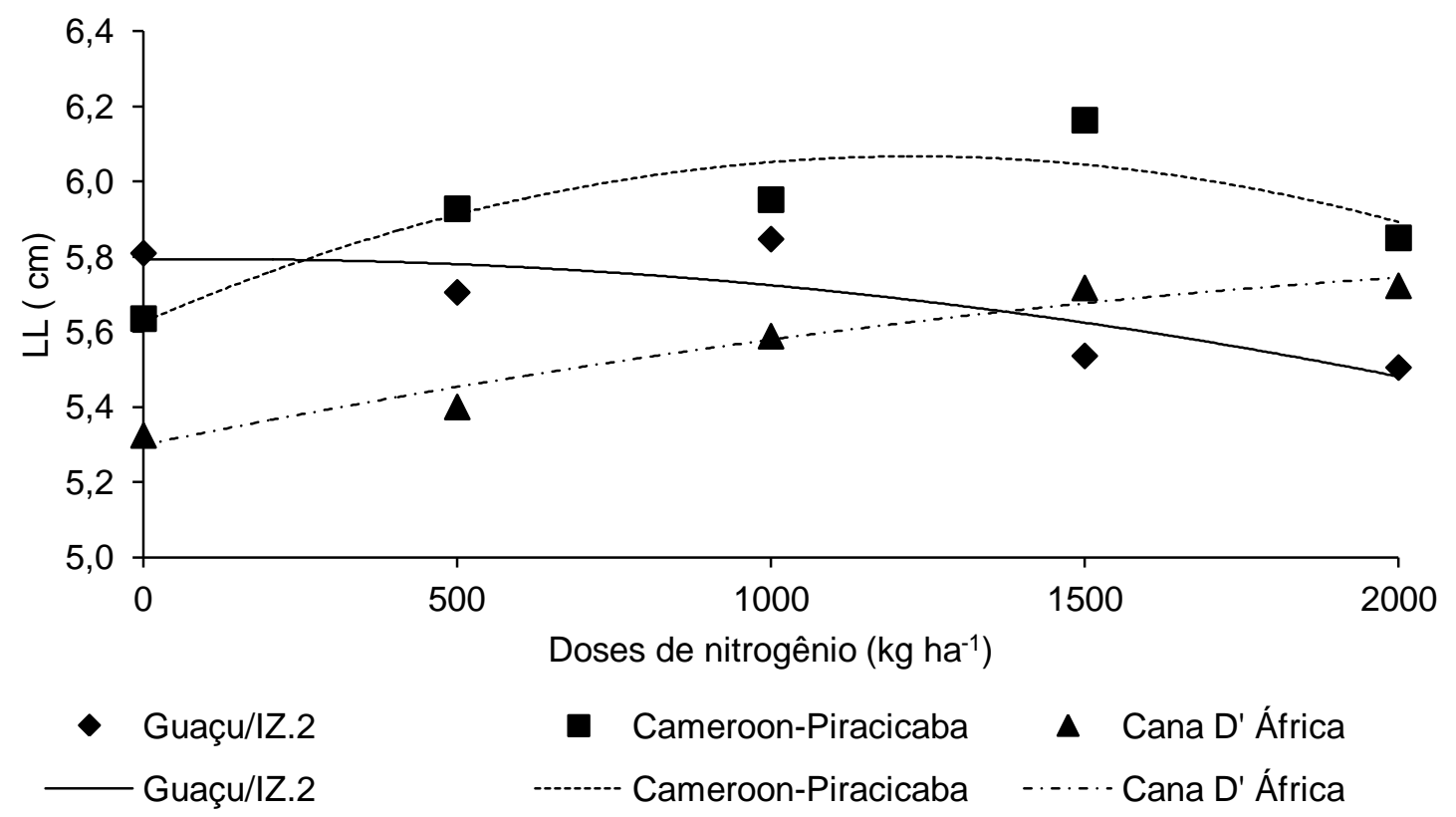

Figura 3 - Largura Média da Lâmina Foliar (LL) de cultivares de capim-elefante em função das doses de nitrogênio. Mean of leaf Blade Width (BW) of elephant grass cultivars as function of nitrogen rates.

A cv. Cameroon-Piracicaba respondeu positivamente ao incremento de $\mathrm{N}$, aumentando a LL nas doses de 500 e $1.500 \mathrm{~kg} \mathrm{ha}^{-1}$ de $\mathrm{N}$, diferindo estatisticamente de 'Cana-D'África' nessas doses e de 'Guaçu/IZ.2' na dose de $1.500 \mathrm{~kg} \mathrm{ha}^{-1}$ de N. Portanto, as respostas dessas cultivares podem ser mais bem explicadas pela equação de regressão obtida, observando-se uma tendência crescente da LL em função da adubação nitrogenada para a cultivar Cana-D'África , em virtude de a equação mais representativa ser de aspecto linear, mostrando grande capacidade de absorção de nitrogênio e indicando potencial para doses ainda maiores, bem como aumento de sua produtividade foliar, enquanto a cv. Cameroon-Piracicaba com a adubação de máxima de $1.238,62 \mathrm{~kg} \mathrm{ha}^{-1}$ de $\mathrm{N}$ proporcionou uma largura máxima de $6,52 \mathrm{~cm}$.

Segundo OLIVEIRA (2012), a cv. Gua-
çu/lZ.2 obteve o melhor ajuste com modelo de $2^{\underline{0}}$ grau para LL, e para a cv. Cameroon-Piracicaba, foi o modelo de $1^{\circ}$ grau. Estas obtiveram regressão com o mesmo nível de significância de 1\% pelo teste F. Dessa forma, pode-se observar que as cultivares apresentam potencial para o aspecto de forragem; no entanto, cabe ressaltar que 'Cameroon-Piracicaba', devido à sua equação mais representativa ser de aspecto linear, mostra grande capacidade de absorção de nitrogênio, indicando potencial para doses ainda maiores, bem como aumento de sua produtividade foliar.

MELLO et al. (2006), analisando clone de capim-elefante em Pernambuco, constataram que a produção de lâmina foliar tem relação positiva com a altura da planta, indicando que as plantas com maior produção de folhas tendem a apresentar maior produção de matéria seca e altura de planta. 


\section{Conclusões}

As doses de fósforo utilizadas não influenciaram nas respostas das três cultivares para as diferentes características morfoagronômicas avaliadas.

As médias das cultivares para as características produção de matéria seca e altura não diferiram entre si, dentro de cada dose de nitrogênio,

A cv. Cameroon-Piracicaba apresentou valores superiores para diâmetro de colmo, tendendo a apresentar maior largura de lâmina e menor número de plantas por metro em relação às cultivares Guaçu/IZ.2 e Cana-D’África.

As doses de nitrogênio proporcionaram respostas significativas para as características produção de matéria seca, número de plantas por metro linear e largura de lâmina, mesmo sob condições de estresse hídrico.

\section{Agradecimentos}

À Universidade Estadual do Norte Fluminense Darcy Ribeiro (UENF), pelo acordo junto à Coordenação de Aperfeiçoamento de Pessoal de Nível Superior (CAPES), pelo apoio ao programa de doutorado interinstitucional (DINTER). E à Fundação Carlos Chagas Filho de Amparo à Pesquisa do Estado do Rio de Janeiro (FAPERJ), pelo auxílio parcial ao desenvolvimento do projeto de pesquisa.

\section{Referências}

ANDRADE, J. B.; FERRARI JUNIOR, E.; BEISMAN, D. A. Avaliação do capim-elefante (Pennisetum purpureum Schum.) visando 0 carvoejamento. In: ENCONTRO DE ENERGIA NO MEIO RURAL, 3., 2000, Campinas. Anais...

\section{AZEVEDO, P. B. M. Aspectos econômicos da} produção agrícola do capim elefante. In: Anais do $3^{\circ}$ Encontro de Energia no Meio Rural-AGRENER. Campinas, Setembro 2003. Disponível em:

http://www.proceedings.scielo.br/scielo.php?pid= MSC0000000022000000100032\&script=sci_artte xt\#figura1>. Acesso em: 17 jun. 2010.

BOTREL, M. A.; PEREIRA, A. V.; FREITAS, V. $P$. Potencial forrageiro de novos clones de capim-elefante. Revista Brasileira Zootecnia, Viçosa, MG, v.29, n.2, p.334-340, 2000.

CARNEVALLI, R. A. Forrageiras utilizadas para bovinos leiteiros. Módulo I. p.12. Disponível em: <http://cpamt.sede.embrapa.br/biblioteca /material-de-curso/modulo-1/plantas\%20forrageiras \%20ii.pdf>. Acesso em: 1 jul. 2013.
CORSI, M. Estudo da produtividade e valor nutritivo do capim-elefante Pennisetum purpureum Schum, variedade Napier, submetido a diferentes frequências e alturas de corte. 1972. 239f. Tese (Doutorado) - Escola Superior de Agricultura "Luiz de Queiroz", Universidade de São Paulo,.Piracicaba, 1972.

DAHER, R. F.; PEREIRA, A. V.; PEREIRA, M. G.; LÉDO, F. J. S.; AMARAL JUNIOR, A. T.; ROCABADO, J. M. A.; FERREIRA, C. F.; TARDIN, F. D. Análise de trilha de caracteres forrageiros do capim-elefante (Pennisetum purpureum Schum.). Ciência Rural. Santa Maria, v.34, p.1531-1535, 2004.

DAHER, R. F.; VÁSQUEZ, H. M.; PEREIRA, A. V.; FERNANDES, A. M. Introdução e avaliação de clones de capim-elefante (Pennisetum purpureum Schum.) em Campos dos Goytacazes, RJ. Revista Brasileira Zootecnia. Viçosa, MG, v.29, p.1296-1301, 2000.

DANALATOS, N. G; ARCHONTOULIS F. G; MITSIOS, I. Potential growth and biomass productivity of Miscanthus giganteus as affected by plant density and $\mathrm{N}$-fertilization in central Greece. Biomass and Bioenergy, Rotterdam, v.31, p.145-152. 2007.

EMBRAPA. Empresa Brasileira de Pesquisa e Agropecuária - EMBRAPA. Sistema brasileiro de classificação de solos. 2.ed. Rio de Janeiro: Embrapa Solos, 2006. 306p.

FLORES, R. A.; URQUIAGA, S. S.; ALVES, B. J. R.; COLLIER, L. S.; ZANETTI, J. B.; PRADO, R. $M$. Nitrogênio e idade de corte na qualidade da biomassa de capim-elefante para fins agroenergético cultivado em Latossolo. Semina: Ciências Agrárias, Londrina, v.16, p.1282-1288, 2012.

KRAUSE, G. H.; WEIS, E. Chlorophyll fluorescence and photosyntheseis: The basics. Annual Review of Plant Physiology and Plant Molecular Biology, Palo Alto, v.42, p.313349, 1991

LEMUS, R.; BRUMMER, E. C.; MOORE, K. J.; MOLSTOD, E.; BURRAS, C. L.; BARKER, M. Biomass vield and quality of 20 switchagrass populations in southern lowa, USA: Biomass and Bioenergy, Oxford, v.23, p.433-442, 2002.

MAZZARELLA, V. N. G. Capim elefante como fonte de energia no Brasil: realidade atual $e$ expectativas. Workshop Madeira Energética. Rio de Janeiro, $2007 . \quad$ Disponível em: http://www.inee.org.br/down_loads/eventos/0945 VicenteMazzarela\%20IPT.ppt>. Acesso em: 25 jun. 2013. 
MELLO, A. C. L.; LIRA, M. A.; BATISTA, J. C.; JÜNIOR, D.; SANTOS, M. V. F.; FREITAS, E. V. Caracterização e Seleção de Clones de CapimElefante (Pennisetum purpureum Schum.) na Zona da Mata de Pernambuco. Revista Brasileira Zootecnia, Viçosa, MG, v.31, n.1, p.30-42, 2002. Disponível em: <http://www.scielo.br/pdf/rbz/v31n1 /8945.pdf>. Acesso em: 6 de jul. 2013.

MORAES, Y. J. B. Forrageiras: conceitos, formação e manejo. Guaíba: Editora Agropecuária, 1995. 215p.

MORAIS, R. F. Potencial produtivo e eficiência da fixação biológica de nitrogênio de cinco genótipos de capim elefante (Pennisetum Purpureum Schum.), para uso como fonte alternativa de energia. 2008. 73f. Dissertação (Mestrado em Agronomia) - Universidade Federal Rural do Rio de Janeiro, Seropédica, 2008.

MORAIS, R. F.; ZANETTI, J. B.; PACHECO, B. M.; JANTALIA, C. P.; BODDEY, R. M.; ALVES, B. J. R.; URQUIAGA, S. Produção e qualidade da biomassa de diferentes genótipos de capimelefante cultivados para uso energético. Revista Brasileira de Agroecologia, Porto Alegre, v.4, n.2, p.1103-1107, nov.2009.

MOREIRA, L. M.; FONSECA, D. M.; MARTUSCELLO, J. A.; NÓBREGA, E. B. Adubação fosfatada e níveis críticos de fósforo no solo para manutenção da produtividade do capim-elefante (Pennisetum purpureum cv. Napier). Revista Brasileira Zootecnia, Viçosa, MG, v.35, n.3, p.943-952, 2006. Disponível em <http://www.scielo.br/pdf/rbz/v35n3s0/30703.pdf> Acesso em: 26 jun.2013.

MOREIRA, P. C.; WASCHECK, R. C.; DUTRA, A. R.; GRANDSIRE, C,; ALMEIDA, O. C.; MOREIRA, S. O. L.; OLIVEIRA, D. L. Utilização de Capim-elefante para alimentação de bovinos. Estudos, Goiânia, v. 35, n. 3, p. 429-449, maio/jun. 2008. Disponível em: $<$ http://www.google.com.br/\#hl=pt-

BR\&sclient=psy-

http://seer.pucgoias.edu.br/index.php/estudos/arti cle/view/743/563>. Acesso em: 26 fev.2013.

MONTI, A; FAZIO, S; LYCHNARASB, P; SOLDATOS, P; VENTURIA, G. A full economic analysis of switchgrass under different scenarios in Italy estimated by BEE model. Biomass and Bioenergy, Rotterdam, v.31, p.177-185, 2007.

NABINGER, C.; MEDEIROS, R. B. Produção de sementes de Panicum maximum Jacq. SIMPÓSIO SOBRE O MANEJO DE PASTAGENS, 12., 1995, Piracicaba. Anais... Piracicaba: Fundação de Estudos Agrários Luiz de Queiroz, 1995. p.59-128.
NASCIMENTO JR., D. Informações sobre plantas forrageiras. Viçosa, MG, UFV- Imprensa Universitária, 1981. 56p.

OLIVEIRA, E. S. Variação de caracteres morfoagronômicos e da qualidade da biomassa em seis genótipos de capim-elefante (Pennisetum purpureum Schum.) em função de diferentes doses de nitrogênio e análise da viabilidade econômica em Campos dos Goytacazes, RJ. 2012. 120 f. Tese (Doutorado em Produção Vegetal)-Universidade Estadual do Norte Fluminense Darcy Ribeiro, Campos dos Goytacazes, 2012.

PEREIRA, A. V.; DAHER, R. F.; PEREIRA, M. G.; LEDO, F. J. S.; SOBRINHO, F. S.; AMARAL JÚNIOR, A. T.; FREITAS, V. P.; PEREIRA, T. N. S.; FERREIRA, C. F. Análise de cruzamentos dialélicos entre capim-elefante (Pennisetum purpureum Schum.) e milheto (Pennisetum glaucum (L.) R. BR. 2. Características bromatológicas. Acta Scientiarum Agronomy, Maringá, v.28, n.2, p.277-285. 2006.

PORTO, M. L. A.; PUIATTI, M.; FONTES, P. C. R.; CECON, P. R.; ALVES, J. C.; ARRUDA, J. A. Produtividade e acúmulo de nitrato nos frutos de abobrinha em função da adubação nitrogenadaBragantia, Campinas, v.71, n.2, p.190-195, 2012. Disponível em: <http://www.scielo.br/scielo.php?script=sci_issuet oc\&pid=0006-870520120002\&lng=pt\&nrm=iso > . Acesso em: 29 ago. 2013.

QUEIROZ FILHO, J. L.; SILVA, D. S.; NASCIMENTO, I. S. Produção de matéria seca e qualidade do capim-elefante (Pennisetum purpureum Schum.) cultivar roxo em diferentes idades de corte. Revista Brasileira Zootecnia, Viçosa, MG, v.29, p.69-74, 2000.

QUESADA, D. M.; BODDEY, R. M.; REIS, V.M.; URQUIAGA, S. Parâmetros qualitativos de genótipos de capim-elefante (Pennisetum purpureum Schum.) estudados para a produção de energia através da biomassa. Seropédica: UFRJ, 2004. (Circular Técnica, 8).

RODRIGUES, L. R. A.; PEDREIRA, J. V. S.; MATTOS, H. B. Adaptação ecológica de algumas plantas forrageiras. Zootecnia, Nova Odesa, v.13, n.4, p.201-218,1975.

SANTOS, M. V. F.; JÚNIOR, J. C. B.; SILVA, M. C.; SANTOS, S. F.; FERREIRA, F. L. C.; MELLO, A. C. L.; FARIAS, I.; FREITAS, E. V. Produtividade e Composição Química de Gramíneas Tropicais na Zona da Mata de Pernambuco. Revista Brasileira Zootecnia, Viçosa, MG, v.32, n.4, p.821-827. 2003. 
SILVA, A. L. C.; SANTOS, M. V. F.; DUBEUX JÚNIOR, B . J. C.; LIRA, M. A.; FERREIRA, L. C.; FREITAS, E. V.; CUNHA, M. V.; SILVA, M. C. Variabilidade e herdabilidade de caracteres morfológicos em clones de capim-elefante na Zona da Mata de Pernambuco. Revista Brasileira Zootecnia, Viçosa, MG, v.39, n.10, p.2132-2140, $2010 . \quad$ Disponível em: <http://www.scielo.br/pdf/rbz/v39n10/05.pdf>, Acesso em: 2 jul. 2013.

SILVA, E.; ROCHA, C. R. Eucalipto e capim elefante: características e potencial produtivo de biomassa. Revista Agrogeoambiental, Inconfidentes, v.2, p.143-152, 2010.

SILVA, D. J.; QUEIROZ, A. C. Análise de alimentos: métodos químicos e biológicos. 3 . ed. Viçosa. UFV, 2002. 235p.

URQUIAGA, S.; ALVES, B. J. R.; BODDEY, R. M Capim-elefante: uma fonte alternativa promissora para a produção de energia. 2006. Disponível em: $<w w w$.infobibos.com/Artigos/2006_2/Capimelefa nte>. Acesso: 26 nov. 2009.

VARGAS. A. A força do capitalismo. Ed: Abri. Revista Veja. São Paulo, v.43, n.32, p.112-116, 2010. Edição 2177.
VEIGA, J. B. Utilização do capim-elefante sob pastejo In: Capim-elefante produção e utilização (Ed. CARVALHO, M. M.; ALVIM, M. J.; XAVIER, D. F.; CARVALHO, L. A.) 2.ed. ver. Brasília: EMBRAPA-SPI; Juiz de Fora: Embrapa-CNPGL, 1997.

VITOR, C. M. T.; FONSECA, D. M.; CÓSER, A. C.; MARTINS, C. E.; JÚNIOR, D. do NASCIMENTO; JÚNIOR, J. I. R. Produção de matéria seca e valor nutritivo de pastagem de capim-elefante sob irrigação e adubação nitrogenada. Revista Brasileira Zootecnia, Viçosa, MG, v.38, n.3, 2009. Disponível em: $<$ http://link.periodicos.capes.gov.br/sfxlcl41?ctx_ve $r=Z 39.88$ 004\&ctx_enc=info:ofi/enc:UTTF8\&ctx_tim=2013-07-01T19\%3A33. Disponível em: http://dx.doi.org/10.1590/S1516-

35982009000300006>. Acesso em: 1 de jul.2013.

XIA, Z.; HONGRU, G.; CHENGLONG, D.; XIAOXIAN, Z.; JIANLI, Z.; NENGXIANG, X. Path coefficient and cluster analyses of yield and morphological traits in Pennisetum purpureum. Tropical Grasslands, Brisbane, v.44, p.95-102, 2010.

WERNER, J. C. Adubação de pastagens. Nova Odessa: Instituto de Zootecnia, Secretária de Agricultura e Abastecimento, 1986. 49p. (Boletim Técnico, 18). 